\title{
Sostenibilidad Fiscal en Colombia
}

\section{Fiscal Sustainability en Colombia}

Jaime Ramírez Plazas

Magister en Derecho de la Universidad Externado de Colombia

Profesor de la Facultad de Derecho de

la Universidad Surcolombiana

Recibido: 25/01/2012 Aprobado: 09/05/2012

jarapla@usco.edu.co

\section{RESUMEN}

El presente artículo pretende hacer una análisis del Acto legislativo No 3 de 2011 por medio del cual se adoptó la sostenibilidad fiscal en Colombia como un principio que debe orientar a las Ramas y Órganos del Poder Público, dentro de sus competencias, en un marco de colaboración armónica y el cual deberá servir como instrumento para alcanzar de manera progresiva y programática los objetivos del Estado Social de Derecho

\section{PALABRAS CLAVE}

Estado, sostenibilidad fiscal, estabilidad macroeconómica

\section{ABSTRACT}

This article wants to make an analysis of the Legislative Act No. 3 of 2011 by which it adopted in Colombia fiscal sustainability as a principle that should guide the branches and public bodies, within their competence, in a collaborative harmonic and which should serve as an instrument for achieving progressively and programmatic objectives of the rule of law.

\section{KEYWORDS}

State fiscal sustainability, macroeconomic stability

\section{INTRODUCCIÓN}

Las funciones económicas del Estado democrático son la acumulación y la legitimación. La primera se entiende como la garantía de la reinversión de las ganancias, mientras la legitimidad hace referencia a la forma como se hace reconocer el Estado. La regulación es una de las formas como el Estado se hace reconocer; de allí la importancia del análisis de la sostenibilidad fiscal como norma que le permite al Estado lograr el desarrollo económico.

Una de las principales novedades que introdujo la Constitución de 1991 fue haber incorporado el concepto de Estado Social de Derecho, que responde igualmente a una tendencia del derecho comparado cuyo origen se remonta a la Constitución de México de 1917 (Trapaga Reyes, J. 2000. p. 5), y en especial, a la República de Weimar de 1919(Trapaga Reyes, J. 2000. p. 6). 
Así pues, la Ley Fundamental de Bonn de 1949 contiene algunas reglas de disciplina fiscal y de limitación de financiación mediante créditos. Posteriormente, en la década de los sesenta, una reforma constitucional sometió el régimen presupuestal al respeto por el equilibrio económico (estabilidad del nivel de precios, alto nivel de empleo, balance externo y crecimiento económico estable). ${ }^{1}$

Así pues, en el caso alemán, la ley Fundamental contiene distintas reglas fiscales, encaminadas a (i) alcanzar un equilibrio global de su economía; y (ii) cumplir con los compromisos asumidos en el contexto de la Unión Europea.

No obstante lo anterior, una revisión del derecho comparado evidencia que, si bien existe una constante preocupación por el tema de la sostenibilidad fiscal, también lo es que, en la mayoría de países, aquélla no ha sido elevada a rango constitucional sino legal.

La sostenibilidad fiscal es un criterio que reconoce la escasez de los recursos públicos y pretende asegurar las condiciones para que el Estado garantice la prestación y el disfrute del conjunto de derechos reconocidos en la Constitución. Se trata de una herramienta para la realización sostenible y eficiente del Estado Social de Derecho, en desarrollo del cual sea posible desplegar razonablemente un proceso democrático de fijación de prioridades y de adopción de políticas públicas para lograr las metas trazadas, sin desconocer, en ningún caso, los derechos reconocidos por la Constitución.

En el presente artículo pretendemos conocer el proceso de constitucionalización de la sostenibilidad fiscal en Colombia establecida mediante Acto Legislativo No 3 de 2011.

\section{EL CONCEPTO DE SOSTENIBILIDAD FISCAL}

La sostenibilidad fiscal se define como la capacidad de un gobierno para atender el pago de su deuda a largo plazo. Así pues, una situación es sostenible cuando se cumplen dos condiciones, a saber: (i) cuando un país puede satisfacer sus restricciones presupuestales en el período actual sin recurrir, por defecto o exceso, a la monetarización de su deuda; $y$ (ii) cuando un Estado no sigue acumulando deuda, a sabiendas de que un futuro ajuste mayor será necesario, en orden a lograr satisfacer el servicio de aquélla

La sostenibilidad fiscal es un asunto que concierne la estabilidad macroeconómica de un país, su crecimiento a largo plazo, al igual que su capacidad para asumir su deuda pública. En otras palabras, la sostenibilidad fiscal exige que el gobierno sea solvente, es decir, que pueda rembolsar su deuda en algún momento en el futuro.

Según el Banco Interamericano de Desarrollo (HA-L1034: sostenibilidad fiscal. 2010), el término "sostenibilidad fiscal", hace que las políticas públicas sean consideradas como fiscalmente sostenibles si conllevan a una situación en la cual el país puede satisfacerlas dentro de sus restricciones presupuestales. En tal sentido, debe diferenciarse del concepto de "solvencia".

Así, un grupo de políticas públicas es insostenible si conduce a la insolvencia, es decir, a una situación en la cual futuras líneas de gasto e ingresos no se satisfacen debido a las restricciones presupuestales intertemporales.

En el mismo sentido, la Subgerencia de Estudios Económicos del Banco de la República, en un estudio titulado "Sostenibilidad fiscal en Colombia: una mirada hacia el mediano plazo", afirma lo siguiente:

1.- En tal sentido, el artículo 109 constitucional alemán dispone lo siguiente:

“ARTÍCULO 109. [GESTIÓN PRESUPUESTARIA DE LA FEDERACIÓN Y DE LOS LäNDER].

(1) La Federación y los Länder son autónomos y recíprocamente independientes por lo que respecta a su gestión presupuestaria.

(2) La Federación y los Länder deberán tener en cuenta en su gestión presupuestaria las exigencias del equilibrio global de la economía." 
"En los medios especializados se suele decir que la posición fiscal de un país es sostenible si el gobierno reconoce y cumple la Restricción Presupuestaria Inter-temporal (RPI). La RPI es un principio de naturaleza contable que describe los factores que inciden en la evolución de la deuda pública. Esa postura también permite hacer pronósticos sobre la trayectoria futura de la deuda y derivar conclusiones básicas de política consistentes con una postura fiscal determinada" (Lozano Ignacio y Cabrera E., 2009, pág. 16).
La economía colombiana ha tenido un desarrollo generalmente favorable en la última década. Así por ejemplo, entre 2002 y 2010 el crecimiento anual promedio fue $4.5 \%$ (muy similar al $4.4 \%$ promedio exhibido por las 7 economías más grandes de América Latina (Caceres, C., Corbacho, C., y L. Medina. 2010)) y la inflación de $5.2 \%$ (el promedio para el $\mathrm{G} 7$ regional fue $8.1 \%$ ). un sinnúmero de medidas en el frente fiscal que llevaron el déficit del Gobierno Nacional Central (GNC) del 6.4\% del PIB en 1999 a $2.3 \%$ en 2008 lo cual condujo a que la relación deuda/PIB bajara de $48.3 \%$ en 2002 a $36 \%$ en 2008.

Cuadro 1. Crecimiento económico y balance primario

\begin{tabular}{ccc}
\hline Pais & $\begin{array}{c}\text { Crecimiento } \\
\text { 2004-2007 }\end{array}$ & $\begin{array}{c}\text { Balance Primario GNC } \\
\text { 2003-2007 }\end{array}$ \\
\hline Argentina & 8.8 & 2.76 \\
\hline Brasil & 4.5 & 2.34 \\
Chile & 5.3 & 6.58 \\
Colombia & 6.2 & -0.33 \\
México & 3.8 & 0.0 \\
\hline Perú & 7.1 & 2.12 \\
\hline
\end{tabular}

Fuente: LatinFocusConsensusForecast, FMI, CEPAL

El hecho de que en los años de boom la posición fiscal mejorara sólo ligeramente explica en gran medida el que la habilidad del gobierno colombiano para adelantar una política fiscal contra-cíclica expansionista durante la reciente crisis resultara inferior a la que tuvieron otros países de la región. Así por ejemplo, el gasto público como porcentaje del PIB aumentó en Colombia apenas un poco más de 1\% del PIB entre 2008 y 2009.

Durante el primer semestre del año 2010 se socializó la idea de que la política fiscal debería desarrollarse en el contexto de una "regla fiscal" que propendiera por la sostenibilidad de la deuda, facilitara la adopción de posturas contra-cíclicas y asegurara que la política fiscal coadyuvaría a mitigar los efectos de "enfermedad holandesa" que podrían derivarse de las muy favorables perspectivas del sector minero-energético (Fedesarrollo, 2010).

\section{EL ESTADO SOCIAL DE DERECHO; LA ECONOMÍA DE MERCADO Y LA INTERVENCIÓN EN LA ECONOMÍA.}

La sostenibilidad fiscal como condición para el desarrollo del Estado Social de Derecho, en la Constitución de 1991, se implementó en la realización efectiva de varios derechos específicos y consiste en adoptar un derecho que contribuye a proteger a todos los demás y a darles continuidad bajo las diferentes condiciones que enfrente la economía para atender sus deberes sociales. De este derecho se deriva el deber de todas las ramas y 
órganos del poder público para que sus decisiones sean acordes con la sostenibilidad fiscal para realizar los propósitos del Estado Social de Derecho.

La sostenibilidad fiscal es importante para el progreso económico y social de un país en la medida en que el sector público busca que, ante una determinada y limitada capacidad para recaudar ingresos y para acceder a recursos de financiamiento, la política de gasto pueda mantenerse o sostenerse en el tiempo, de manera que en el mediano y en el largo plazo se logren importantes objetivos públicos, como la reducción de la pobreza, la desigualdad, la equidad intergeneracional, y un crecimiento económico estable. En otras palabras, el Gobierno protege la sostenibilidad fiscal cuando la senda de gasto que adopta en el presente no socava su capacidad para seguir gastando en la promoción de los derechos sociales y en los demás objetivos del Estado en el mediano plazo.

Alcanzar y garantizar la sostenibilidad no es fácil y requiere de un gran compromiso y disciplina del sector público y del apoyo de la sociedad en la búsqueda de este objetivo. De no garantizarla, los riesgos y los costos económicos y sociales pueden ser elevados. Eso no sólo lo ha demostrado la literatura económica sino también se ha evidenciado con la experiencia de muchos países en las últimas décadas, inclusive en tiempos recientes.

Así las cosas, las autoridades económicas deben estar comprometidas con el logro de los objetivos de política económica, inflación baja y estable, y sostenibilidad fiscal, que permita la efectividad de las políticas de estabilización macroeconómica, al lograr minimizar las fluctuaciones del ciclo económico. Esta situación promovería mejores perspectivas hacia el crecimiento económico en el mediano plazo favoreciendo así el mayor acceso de los ciudadanos a los bienes y servicios a los que tienen derecho. De lo contrario, fuertes fluctuaciones del ciclo económico se reflejarían en desequilibrios económicos que se traducen en un mayor desempleo, alta inflación y alteraciones en los mercados financieros que obstaculizan la realización de los planes de consumo e inversión por parte de los hogares y las empresas.

Por esta razón, además de preservar el poder adquisitivo de la moneda, que por sí solo no garantiza el bienestar de la sociedad, los objetivos de la intervención del Estado en la economía, establecidos en la Constitución Política, y orientados especialmente a dar pleno empleo a los recursos humanos y asegurar el acceso de todas las personas a los bienes y servicios básicos, en particular por parte de las de menores ingresos, se fortalecen con un objetivo de política económica como la sostenibilidad fiscal.

Por consiguiente, la materialización del Estado Social de Derecho requiere también de una economía promovida por un dinamismo sostenible. En la medida en la que se asegure la sostenibilidad fiscal, mayores serán las posibilidades de hacer efectivos los derechos sociales, económicos y culturales, y aumentará igualmente el número de personas con acceso a los bienes y servicios básicos.

De allí entonces la importancia de poder contar con un marco de sostenibilidad fiscal, que ofrezca a los agentes económicos -tanto públicos como privadosun ambiente propicio para la inversión y la generación de empleo. Ese es el marco de sostenibilidad fiscal que, desde la Constitución, debería servir de orientación a todas las autoridades del Estado, tal como establece el artículo primero del Acto Legislativo No 3 de 2011.

La nueva Carta Política llevó a proclamar a Colombia como un Estado Social de Derecho, y a preconizar, dentro de sus fines esenciales, los de "promover la prosperidad general y garantizar la efectividad de los principios, derechos y deberes consagrados en la Constitución"

Desde esa profunda perspectiva, el Título II, Capítulo 2, se ocupa de los derechos económicos, sociales y culturales también llamados por la doctrina como de "segunda generación", y consagra una amplia y 
variada lista de derechos que el Estado debe procurar hacer efectivos, tales como a la seguridad social, a la vivienda digna; a la educación y, como parte de ésta, el deporte y la recreación.

Haciéndose eco de la misma preocupación humanística, el artículo 366 expresa que el bienestar social y el mejoramiento de la calidad de vida de la población son finalidades sociales del Estado, y que será objetivo fundamental de su actividad la solución de las necesidades insatisfechas de salud, de educación, de saneamiento ambiental y de agua potable. Y, en plena concordancia con esas ideas, el artículo 365 de la Carta Política señala que los servicios públicos son inherentes a la finalidad social del Estado, y que es deber suyo asegurar su prestación eficiente a todos los habitantes del territorio nacional.

Como puede observarse, se trata de un amplio y noble enunciado de derechos sociales y económicos, que el Estado tiene el deber de promover, proteger o hacer efectivos en el marco del Estado Social de Derecho. No es extraño, por ello, que para dar contenido práctico a ese postulado, el artículo 350 de la Constitución Política haya querido que una parte especial de la política fiscal se organice dentro del concepto de "gasto público social", y que todo lo que con él se relaciona haya recibido prioridad sobre los demás gastos que reciben apropiaciones en el presupuesto público.

Sin embargo, pese a la importancia del "gasto público social", el compromiso de las autoridades con el Estado Social de Derecho no se agota, de ninguna manera, en el terreno de las apropiaciones presupuestales. Parte sustancial de ese compromiso consiste, también, en defender la capacidad adquisitiva de la moneda, para que el ingreso que los colombianos obtienen con su trabajo o por subsidios de las autoridades, pueda servirles, efectivamente, para atender sus necesidades y lograr sus aspiraciones. Es incompatible con el Estado Social de Derecho la tolerancia con una moneda que pierda valor constantemente, que crea una ilusión temporal de bienestar destinada a esfumarse en un alza de precios, escasez o desempleo.

$Y$ hay otros aspectos de nuestra Constitución Política, que hacen relación al comportamiento de la economía en vista de las finalidades del Estado Social de Derecho, en punto a la satisfacción de las necesidades básicas de la población colombiana y a la materialización de sus derechos sociales. Se hará en seguida mención de ellos, para subrayar, luego, la importancia de complementarlos con la consagración del derecho a que todos las ramas y órganos del poder público adopten sus decisiones y tomen acciones acordes con la sostenibilidad fiscal para realizar los propósitos del Estado Social de Derecho

En efecto, nuestra Constitución Política define los principios fundamentales de la actividad económica, en el Título XII de la Carta, para permitir el cumplimiento de los fines del Estado Social de Derecho, acogiendo muchas de las reglas que rigen el funcionamiento de las economías de mercado, por oposición al de las economías centralmente planificadas o socialistas.

Las economías de mercado descansan sobre unos pilares fundamentales, dentro de los cuales se destacan el respeto a la propiedad privada (Artículo 58 de la Carta Política) y la libertad económica (artículo 333), dentro de los límites del bien común, la empresa como base del desarrollo, la protección de la libre competencia económica, y la posibilidad de que los servicios públicos sean prestados no sólo por el Estado sino también por los particulares y por las comunidades organizadas(artículo 365).

Dentro de este marco, y habida consideración de las fallas e imperfecciones que suelen presentarse en el funcionamiento del mercado, el Estado se reserva para sí la dirección general de la economía. Así, el artículo 334 de la Constitución Política, mantuvo con algunas modificaciones el esquema básico de intervención del Estado en la economía, que se había introducido dentro de nuestro ordenamiento constitucional desde el año 1936 (Restrepo Piedrahita, Carlos, 1995, págs. 439-447). 
De acuerdo con el mencionado precepto, el Estado está llamado a intervenir, por mandato de la ley, en las distintas manifestaciones de la actividad económica (explotación de los recursos naturales, uso del suelo, producción, distribución, utilización y consumo de bienes, servicios públicos y privados), para racionalizarla, y para lograr ciertos objetivos superiores o finales, a saber: (1) el mejoramiento de la calidad de vida de los habitantes;(2)la distribución equitativa de las oportunidades y los beneficios del desarrollo y (3) la preservación de un ambiente sano.

Según el mismo texto constitucional, la intervención del Estado en la economía debe orientarse de manera especial a: (1) dar pleno empleo a los recursos humanos y (2) asegurar el acceso de todas las personas a los bienes y servicios básicos, en particular de las de menores ingresos.

Finalmente, el precepto superior señala que son también objetivos de la intervención del Estado en la economía promover: (1) la productividad, (2) la competitividad y (3) el desarrollo armónico de las regiones.

Estos objetivos, tienen un carácter eminentemente instrumental, es decir, no son fines en sí mismos, sino medios o requisitos para el logro de los fines últimos de la intervención, que terminan en buena medida siendo los mismos que propone, en términos más generales, el Estado Social de Derecho.

Lo dispuesto en el artículo 334 respecto de la dirección general de la economía por parte del Estado, se complementa y refuerza a través de otras disposiciones constitucionales, dentro de las cuales importa destacar, por un lado, la del artículo 339, relativa al Plan Nacional de Desarrollo y los planes de desarrollo de las entidades territoriales, y, por el otro, la muy importante norma que en buena hora adoptó el Constituyente de 1991, en lo que concierne a la obligación que tiene el Estado de velar, por intermedio del Banco de la República, por el mantenimiento de la capacidad adquisitiva de la moneda (artículo 373).
Sin embargo, como puede apreciarse, el artículo 334 de la Constitución Política, al definir los objetivos de la intervención del Estado en la economía, no hace referencia expresa a la sostenibilidad fiscal.

Esta omisión no alcanza a suplirse por lo dispuesto en el artículo 373 de la misma, respecto de la responsabilidad que tiene el Banco de la República de velar por el poder adquisitivo de la moneda, variable ésta sin lugar a dudas indispensable para alcanzar el objetivo social de la estabilidad de precios, pero insuficiente, por sí sola, para asegurar una sostenibilidad fiscal general.

La existencia de la jurisprudencia que adelante se detalla, además de instrumentos legislativos de racionalidad fiscal, como el Estatuto Orgánico de Presupuesto y en especial la ley 819 de 2003, pese a su importancia de leyes orgánicas, carecen de una jerarquía y rango suficientes para dar a las personas en Colombia una garantía homogénea, estable y exigible a todos los órganos del Estado, de que se mantendrán las condiciones de sostenibilidad fiscal necesarias para asegurar la efectividad de los derechos económicos y sociales.

Para el gobierno era necesario tener una disposición constitucional expresa que contenga un derecho de todos que garantice que el Estado tendrá las condiciones, dentro de sus propias limitaciones de recursos, de garantizar la prestación y el disfrute de los derechos económicos, sociales y culturales, y por ende una realización sostenible y eficiente del Estado Social de Derecho, al tiempo que imponga un deber a las ramas y órganos del poder público de proteger con sus decisiones y actuaciones el mencionado derecho.

\section{MARCO JURÍDICO DE LA SOSTENIBILIDAD FISCAL, ESTABILIDAD MACROECONÓMICA Y PROGRESIVIDAD DE LOS DERECHOS.}

En cuanto a la naturaleza jurídica de la sostenibilidad fiscal establecida en el Acto Legislativo No 3 de 2011, queda claro que se trata de un simple criterio orientador de la actividad de todas las 
ramas y órganos del Estado, incluida la jurisdicción constitucional. No se trata, por el contrario, de un derecho fundamental ni de un principio constitucional de la misma entidad que aquellos previstos en el Título I Superior. De tal suerte que, en adelante, todas las entidades del Estado no sólo deben actuar de manera armónica sino que al momento de ejercer sus respectivas competencias y facultades deben trabajar conjuntamente a efectos de alcanzar la sostenibilidad fiscal del Estado.

La inclusión de la sostenibilidad fiscal como instrumento para "alcanzar de manera progresiva los objetivos del Estado Social de Derecho" se incardina dentro de los postulados del Estado Social de Derecho. En efecto, el principio de progresividad en materia de derechos económicos sociales y culturales se encuentra consagrado en el artículo 48 de la Carta, el cual dispone que "El Estado, con la participación de los particulares, ampliará progresivamente la cobertura de la seguridad social".

De igual manera, el principio de progresividad de los derechos económicos, sociales y culturales DESC-, y su correlativa prohibición de regresión, se encuentran estipulados en diversos instrumentos internacionales de derechos humanos, al igual que en normas de softlaw. ${ }^{2}$

Las distintas disposiciones de los instrumentos internacionales que conforman el sistema americano de protección de los derechos humanos, prevén que (i) los Estados partes deben adoptar progresivamente medidas para lograr la mayor satisfacción posible de los DESC; (ii) tomando en consideración los recursos disponibles, así como su grado de desarrollo.

Ahora bien, partiendo de que la sostenibilidad fiscal apunta a alcanzar la estabilidad macroeconómica de un país y a que, en últimas, cuente con los recursos económicos necesarios para satisfacer su deuda pública, no se entiende que exista una contradicción entre aquélla y el principio de progresividad y la prohibición de regresión en materia de DESC.

En efecto, un Estado insolvente internacionalmente, como ha sucedido incluso con países europeos, no puede tampoco realizar progreso alguno en materia de satisfacción de DESC. Sin duda, por su naturaleza, los avances en términos de garantía de aquéllos presuponen que el Estado se encuentre en capacidad de financiar la provisión de tales derechos, bien sea, principalmente, mediante un incremento en su tributación o la suscripción de empréstitos internacionales.

En suma, sostenibilidad y progresividad no son términos antagónicos o contradictorios. Todo lo contrario. Los avances en materia de DESC presuponen que el Estado pueda honrar sus compromisos internacionales en lo atinente al pago de su deuda externa.

Quiere ello significar que, en adelante, la sostenibilidad fiscal se erige como un mandato de actuación coordinada entre todas las entidades del Estado, incluidos los jueces. Para ello, será necesario contar con información veraz y actualizada acerca de la situación económica de la Nación y de las entidades territoriales, a efectos de que los jueces, al momento de decidir, puedan tomar como elemento de juicio 0 criterio orientador, la preservación de la sostenibilidad fiscal. Aquello, como se puede observar, no atenta contra su autonomía, por cuanto se trata, como se ha explicado, de cumplir con un mandato de actuación coordinada, más no como una intromisión en la decisión. Todo ello dentro de un concepto de legalidad estricta.

El propósito del Acto Legislativo No 3 de 2011, es señalar al Congreso, así como a los demás órganos del Estado en todos los niveles, y según sus competencias, el deber de buscar, en forma deliberada, que sus diferentes decisiones faciliten el logro de una sostenibilidad fiscal, como instrumento

2.- El término "ley blanda" se refiere a los instrumentos de cuasi-jurídicos que no tienen carácter jurídicamente vinculante, o cuya fuerza vinculante es algo "más débil" que la fuerza vinculante del derecho tradicional. 
de protección de los derechos sociales de los colombianos, y como tal, de la realización de los fines del Estado Social de Derecho.

Es decir, hay precedentes jurisprudenciales, al menos en un ámbito particular, que se refieren a la interrelación entre inflación, estabilidad macroeconómica y sostenibilidad fiscal, en particular se pronunció en la Sentencia C-408 de 1994 MP Fabio Morón Díaz, Sentencia C-481 de 1999 MP Alejandro Martínez Caballero, Sentencia C-033 de 1999 MP Carlos Gaviria Díaz, Sentencia C-1489 de 2000 MP Alejandro Martínez Caballero, Sentencia C-579 de 2001 MP Eduardo Montealegre Lynett, Sentencia C-802 de 2006 MP Manuel José Cepeda Espinosa, Sentencia C-242 de 2009 MP Mauricio González Cuervo.

La conclusión que se deriva de los pronunciamientos de la Corte Constitucional, es que la sostenibilidad financiera es un principio sobre el cual se soporta la plena realización de los derechos de las personas dentro de un Estado Social de Derecho, teniendo en cuenta el hecho esencial de que toda sociedad dispone de una cantidad limitada de recursos con los cuales debe atender múltiples necesidades de las personas.

La jurisprudencia de la Corte Constitucional, ha sido amplía en cuanto a la obligación que tiene el Estado de hacer efectivos los derechos económicos y sociales, y satisfacer las necesidades básicas de las personas, lo cual ha de cumplirse de manera progresiva, y no siempre en forma inmediata.

De igual manera, los instrumentos internacionales en materia de Derechos Económicos, Sociales y Culturales han entendido que la progresividad en el reconocimiento, en conjunto, de estos derechos es una nota esencial de los mismos y depende de la cantidad de recursos de que el Estado disponga para tal efecto; se reconoce, también, que los recursos deben ser empleados de la manera más eficiente posible, como lo dispuso el Comité de Derechos Económicos, Sociales y Culturales de Naciones Unidas en la Observación No. 3 "La índole de las obligaciones de los Estados Partes (párrafo 1 del artículo 2 del Pacto)".

Sobre el particular, la Corte Constitucional se ha pronunciado siguiendo los lineamientos del Comité de Derechos Económicos, Sociales y Culturales. El tribunal ha reconocido las limitaciones económicas que subyacen a la realización de estos derechos y dispone como principal obligación del Gobierno la implementación de las medidas necesarias para avanzar en ese sentido.

Se resalta entonces, cómo la jurisprudencia constitucional ha reconocido la importancia que tiene en el ámbito internacional la progresividad en el otorgamiento de los derechos económicos, sociales y culturales entendidos en su conjunto y que el cumplimiento de dichos postulados se soporta en el aprovechamiento máximo de los recursos con que cuenta el Estado, lo cual justifica constitucionalmente la modificación de la misma, puesto que sólo dentro de un ambiente de sostenibilidad fiscal, es posible la realización plena del Estado Social de Derecho privilegiando el interés general sobre el particular, tal como ya exige el artículo $1^{\circ}$ de nuestra Constitución.

Finalmente, no sobra destacar que la jurisprudencia resalta la importancia que se le da a la preservación de la estabilidad macroeconómica. Es importante aclarar que para alcanzarla es requisito necesario, más no suficiente, la sostenibilidad fiscal.

Tenemos que la sostenibilidad fiscal es un requisito para garantizar la prestación de los derechos económicos, sociales y culturales como parte esencial del Estado Social de Derecho y que la misma facilita la progresividad en la atención del conjunto de los derechos, teniendo como marco la disponibilidad de recursos destinados para ello, encontrando como fundamento superior la prevalencia del interés general y atendiendo las prioridades de gasto de acuerdo con las disposiciones constitucionales tal y como lo prevé, por ejemplo, el artículo 350 de la Constitución.

En este orden de ideas, importa detenerse a 
examinar dos aspectos fundamentales de la manera en que el Estado está llamado a cumplir su deber constitucional de hacerlos efectivos, en su conjunto, los derechos económicos y sociales.

Dichos aspectos pueden resumirse de la siguiente manera:

(1) Las limitaciones fiscales, vale decir, la escasez de recursos para financiar el gasto público social, hace necesario que el Estado diseñe unas políticas públicas que permitan un avance sostenido en el cumplimiento de los derechos sociales, teniendo en consideración las posibilidades fiscales. Lo anterior, por supuesto, es requisito indispensable para alcanzar la estabilidad macroeconómica.

(2) Desde el punto de vista de la distribución de competencias en el Estado, corresponde ante todo al legislador, en coordinación con el ejecutivo, definir el contenido y alcance concretos de los derechos sociales y económicos, sin dejar de tener en cuenta la situación fiscal y de la política económica general. Dicho alcance deberá, en cada caso particular e incluso en ocasiones de manera general, ser aplicado por los jueces, lo cual resalta la importancia de la colaboración de todas las ramas y órganos del poder público de alcanzar una sostenibilidad fiscal que garantice, de manera efectiva la prestación y el goce de los derechos, dentro de las garantías y limitaciones impuestas al Estado.

Una de las principales novedades que ofrece el Acto Legislativo 03 de 2011 consiste en crear un "incidente de impacto fiscal", pues antes que ser una medida encaminada a prohibir que los jueces adopten decisiones que comporten un fuerte impacto económico, lo que hace es regular tal facultad, con el fin de alcanzar un fin que se considera importante, como lo es la sostenibilidad fiscal, pero, al mismo tiempo, se les prohíbe que restrinjan o nieguen la protección de los DESC conforme lo dispone el parágrafo del artículo primero del Acto legislativo cuando establece lo siguiente: "bajo ninguna circunstancia, autoridad alguna de naturaleza administrativa, legislativa o judicial, podrá invocar la sostenibilidad fiscal para menoscabar los derechos fundamentales, restringir su alcance 0 negar su protección efectiva".

Pues bien, una forma para superar tal paradoja podría ser entender la forma como se amparan las dimensiones subjetiva y objetiva de los derechos fundamentales.

Por primera vez, se ha pretendido hacer lo propio con el quehacer de la Rama Judicial, en especial, con el juez constitucional. Sin embargo, se estima que ello sólo es así cuando se pretenda amparar la dimensión objetiva, más no la subjetiva, de los DESC, pues en su dimensión subjetiva de un DESC seguiría simplemente lo prescrito por el propio Acto Legislativo no terminará sucediendo lo mismo con la dimensión objetiva de los DESC, por las siguientes razones.

Cuando la Corte Constitucional ha decidido amparar la dimensión objetiva de los DESC, en especial, mediante la figura del "estado de cosas inconstitucional", su actuación no se ha limitado a ordenar el cumplimiento de una prestación específica a cargo del Estado, sino que ha ampliado el alcance de protección de un derecho, no sólo en relación con el número de titulares de aquél, sino en relación con el contenido y alcance mismo del derecho fundamental. ${ }^{3}$

En otras palabras, si bien la sostenibilidad fiscal no puede ser invocada para "menoscabar los derechos

3.- Así por ejemplo, cuando la Corte en sentencia T- 760 de 2008 ordenó igualar los Planes Obligatorios de Salud de los Regímenes Contributivo y Subsidiado, su orden no sólo termina beneficiando a un número elevado de personas, sino que, una vez ejecutada la aquélla, el contenido del derecho a la salud no será el mismo de antes. Adviértase que, en ese caso concreto, el deber de colaboración armónica que vincula a la Corte en materia de sostenibilidad fiscal conduciría a que, si bien tales órdenes podrían seguir siendo adoptadas en el futuro, el juez constitucional deberá tomar en cuenta el criterio orientador de la sostenibilidad fiscal, e igualmente, procedería eventualmente el incidente de impacto fiscal. Aquella fue, por lo demás, la voluntad del constituyente derivado, evidenciada en múltiples ponencias y debates congresionales. 
fundamentales, restringir su alcance 0 negar su protección efectiva" (dimensión subjetiva) a contrario sensu, si podrá serlo cuando se pretenda ampliar el contenido de un derecho fundamental (dimensión objetiva).

\section{LAREGLAFISCAL Y EL PRINCIPIO DE SOSTENIBILIDAD FISCAL EN COLOMBIA}

Una adecuada comprensión del término "sostenibilidad fiscal" pasa por establecer algunas relaciones con otro concepto afín, cual es, aquel de regla fiscal.

Así pues, según Kopits y Symansky (Lozano Ignacio, Rincón H., Sarmiento M., y Ramos Jorge. 2008. pág. 37), una regla fiscal es definida como "una restricción permanente a la política fiscal mediante simples límites numéricos sobre el total del presupuesto". De tal suerte que, la aplicación de reglas fiscales puede apuntar, junto con otros instrumentos económicos, a alcanzar la sostenibilidad fiscal de un determinado país. A respecto, son importantes las reglas fiscales que apuntan a (i) determinar presupuestos balanceados; (ii) normas y procedimientos relacionados con el manejo de la deuda pública; (iii) reglas sobre gasto; y (iv) disposiciones sobre manejo de rentas estatales.

Las propiedades de la regla, cuenta con diferentes características, dentro de las cuales vale la pena destacar:

1. Permite asegurar un nivel menor de deuda en el mediano plazo.

2. Hace explicito el objetivo de la política fiscal, con lo cual se promueve la estabilidad, disciplina y blindaje del manejo fiscal en el mediano plazo.

3. Independiza el objetivo fiscal y las decisiones de política de movimientos cíclicos de la economía, en particular del producto y de los ingresos petroleros, por lo que la regla es de naturaleza estructural.

4. Permite un espacio para la política fiscal contracíclica, lo cual significa que la autoridad puede ahorrar en momentos de recesión y gastar en momentos de auge, sin que se comprometa la meta de mediano plazo.

5. Posibilita un mejor manejo macroeconómico de los excedentes que genera el sector minero-energético.

6. Evita los problemas de credibilidad y monitoreo que genera una regla definida sobre el ciclo económico.

El diseño de la regla fiscal deberá tener en cuenta tanto los aspectos técnicos relativos a la regla, como los requisitos institucionales y jurídicos que permiten su operatividad, seguimiento y cumplimiento.

Desde el punto de vista jurídico, la regla fiscal deberá tener un carácter de ley orgánica con el fin de garantizar una especial jerarquía frente a las demás leyes.

Así mismo, la regla fiscal deberá condicionar la elaboración de los diversos instrumentos de manejo fiscal existentes como el plan financiero, el marco fiscal de mediano plazo y el marco de gasto de mediano plazo, con el fin de establecer metas cuantitativas que permitan involucrar a la regla con cada uno de estos instrumentos independientemente de la cobertura de tiempo de cada uno de ellos.

Ahora bien, de acuerdo con Cottarelli, las reglas fiscales cuentan con una larga historia. En tal sentido, desde mediados del siglo XIX, algunas entidades territoriales de Estados federales fueron sometidas a diversas reglas fiscales, en orden a evitar grandes déficits. Luego de la Segunda Guerra Mundial, Alemania, Italia, Japón y los Países Bajos, incorporaron reglas sobre presupuestos balanceados para los gobiernos centrales, en el ámbito de programas de estabilización.

Posteriormente, debido a los excesivos déficits fiscales acumulados durante la década de los años setentas y ochentas, un número creciente de Estados adoptaron políticas encaminadas a establecer limitaciones presupuestales, incluyendo 
los Estados Unidos de América (Gramm-RudmanHollingsAct of 1985, remplazado por el Budget EnforcementAct of 1990); Canadá (Federal Spending Control Act of 1991), así como varios países de Latinoamérica.

Más recientemente, la Unión Europea ha adoptado regulaciones supranacionales, contentivas de reglas fiscales para sus países miembros, tales como el Tratado de Maastricht (1992), Pacto de Estabilización para el Crecimiento (1997), textos normativos encaminados a lograr las condiciones para consolidar una unión monetaria. Aunado a lo anterior, los Estados Partes han complementado el marco comunitario con reglas fiscales nacionales.

Para el año 2009, según datos del Fondo Monetario Internacional, cerca de 80 países han adoptado medidas nacionales o supranacionales contentivas de reglas fiscales: 21 países desarrollados; 33 mercados emergentes y 26 países en vía de desarrollo.

En suma, en la mayoría de los casos, las reglas fiscales son diversos instrumentos y medidas normativas encaminadas a alcanzar la sostenibilidad fiscal de un país.

En FMI (2010) se aporta evidencia de que las reglas fiscales en el nivel nacional están asociadas con una mejora en el desempeño fiscal. En particular, señala que para los países de la Unión Europea las reglas fiscales más estrictas y comprehensivas están correlacionadas con un balance primario estructural más fuerte.

Las reglas fiscales no son nuevas en Colombia y de tiempo atrás han existido reglas que afectan el sendero de las finanzas de los gobiernos subnacionales. Así por ejemplo, la Ley 358 de 1997 introdujo límites cuantitativos a su endeudamiento y la Ley 617 de 2000 estableció límites al crecimiento de sus gastos. Los efectos de estas nuevas instituciones fiscales han sido significativos.

Durante los últimos quince años se han incorporado algunas medidas dirigidas a procurar la sostenibilidad y a guiar la política fiscal en el país; los ejemplos más conocidos son:

I. Estatuto Orgánico de Presupuesto: Contenido en el DECRETO 111 DE 1996 buscan a través de los principios de coherencia macroeconómica y homeóstasis presupuestal, mantener las condiciones de sostenibilidad

II. Ley de Semáforos o Ley 358 de 1997: estableció un conjunto de medidas cuantitativas para restringir el endeudamiento de los gobiernos territoriales de acuerdo con su capacidad de pago.

III. Ley 617 de 2000 o Ley de Responsabilidad Fiscal Territorial: fijó criterios cuantitativos para limitar el crecimiento del gasto de funcionamiento de los entes territoriales y del GNC.

IV. Ley 819 de 2003: estipuló reglas para proporcionar transparencia y responsabilidad fiscal en el sector público no financiero, haciendo obligatoria la presentación anual del marco fiscal de mediano plazo, con un marco de gasto para un horizonte de cuatro años.

V. Ley 1448 de $2011^{\circ}$ ley de víctima se lee lo siguiente: Para efectos de cumplir con las medidas de ayuda humanitaria, atención, asistencia y reparación dispuestas en el presente marco,

VI. Ley 1454 de 2011 "Por la cual se dictan normas orgánicas sobre ordenamiento territorial y se modifican otras disposiciones", se establece en términos de "principio rector del ordenamiento territorial", a la sostenibilidad fiscal:

VII. Ley 1473 de 2011 específicamente consagra y desarrolla una regla fiscal, de largo plazo de las finanzas públicas y contribuyan a la estabilidad macroeconómica del país.

Así pues, como puede apreciarse en el ámbito legal colombiano existen numerosas leyes, sean ordinarias u orgánicas, que estipulan reglas fiscales encaminadas a (i) sanear las finanzas públicas, en especial, aquellas de las entidades territoriales; (ii) imponer obligaciones al Gobierno Nacional al momento de elaborar el presupuesto nacional; (iii) racionalizar el gasto público; y, en definitiva (iv) lograr niveles de sostenibilidad fiscal. 
Los buenos resultados que Colombia pueda obtener de una regla fiscal como la recién descrita van a estar en gran medida condicionados por una realidad ineludible. A saber, se trata de un país donde, evidentemente, el órgano ejecutivo del poder público no tiene monopolio sobre la iniciativa de gasto público. A partir de la Constitución de 1991, la iniciativa de leyes que decreten gasto público es compartida entre el Ejecutivo y el Legislativo. Además, la Corte Constitucional también tiene iniciativa de gasto y algunos de sus fallos están asociados a enormes costos fiscales (FMl. 2010). Tal es el caso de decisiones relacionadas con la indexación del salario mínimo, las cuales han tenido gran impacto sobre los ajustes salariales de los empleados públicos y de las pensiones, por sólo mencionar un caso.

Por no detentar el monopolio de la iniciativa de gasto, el gobierno colombiano, había considerado deseable que la Regla Fiscal sea complementada con una enmienda a la Constitución que establezca la sostenibilidad fiscal como un principio que debió ser tenido en cuenta por todas las instancias del poder público con capacidad de decretar gasto.

Los instrumentos actuales de racionalidad fiscal y la eventual regla fiscal carecen de jerarquía y rango suficientes para asegurar la coordinación de todos los órganos del Estado en la consecución de la sostenibilidad fiscal. Es poco democrática la disociación que existe en el país entre los derechos y su exigibilidad por un lado, y los deberes de tributar y la racionalidad de unos recursos limitados por el otro, y pareciera que es una responsabilidad exclusiva de la autoridad fiscal garantizar que el balance es sostenible.

El Gobierno Nacional, pretendió que estas omisiones pudieran superarse con la aprobación del Acto Legislativo que tuvo como objetivo mejorar el orden del manejo de las finanzas públicas a través del establecimiento de una meta de balance primario que permita reducir progresivamente la deuda del gobierno nacional central (GNC), a través de la incorporación de la figura de la sostenibilidad fiscal para alcanzar los fines del Estado social de derecho.

El propósito original de esta reforma era crear una tensión explícita entre el nuevo derecho a la sostenibilidad y los derechos sociales y económicos especialmente en el ámbito judicial.

En este orden de ideas, la inclusión del concepto de sostenibilidad fiscal en la Constitución, antes que configurar una sustitución de la misma, configura un paso más en una larga evolución normativa que, hasta el momento, se había dado exclusivamente en el ámbito legal.

El proyecto de reforma constitucional sobre la sostenibilidad fiscal fue un proceso poco edificante. Inicialmente el gobierno Uribe en sus postrimerías le propuso al Congreso adoptar en la Constitución el derecho a la sostenibilidad fiscal; se abstuvo de proponer las reglas cuantitativas que habrían de definir la sostenibilidad fiscal en Colombia; tampoco precisó los agentes estatales responsables de esta definición.

Como se pudo apreciar, en el proyecto de reforma constitucional, el Gobierno Nacional propuso elevar a rango constitucional la sostenibilidad fiscal, calificándola como "derecho de todos" y, correlativamente, "deber de todas las ramas y órganos del poder público", para lo cual, estas últimas debían "colaborar armónicamente, dentro de sus competencias, para hacerla efectiva".

En cuanto a los principales argumentos presentes en la exposición de motivos se tenían los siguientes: (i) la sostenibilidad fiscal es una condición para el desarrollo del Estado Social de Derecho; (ii) se trata igualmente de un derecho que contribuye a proteger a todos los demás derechos; y (iii) la sostenibilidad fiscal y la estabilidad macroeconómica son presupuestos necesarios para el reconocimiento y ejercicio de los derechos.

La exposición de motivos que acompañaba al texto original del proyecto reitera que la propia Corte 
Constitucional ha defendido:

a. La necesidad de que exista coordinación entre las funciones del Banco de la República y la ejecución de la política económica general, a favor de los objetivos generales del Estado Social de Derecho.

b. La intervención del gobierno nacional en las finanzas de las entidades territoriales como instrumento para conjurar una crisis estructural de éstas, que podría amenazar la sostenibilidad fiscal y la estabilidad macroeconómica.

c. La preeminencia de la sostenibilidad financiera del sistema general de pensiones sobre los intereses particulares de los beneficiarios de regímenes especiales.

d. La prevalencia de la protección general de los derechos económicos y sociales sobre la prestación de algún derecho particular, para asegurar que el conjunto de aquellos sea reconocido de manera progresiva.

Sobre la base de este llamado implícito a la coherencia jurisprudencial de la Corte, el gobierno concluye que los altos jueces han defendido la superioridad de los principios de sostenibilidad fiscal y de estabilidad macroeconómica, como condición para que el Estado no falle en sus objetivos sociales fundamentales. De allí procede a plantear la necesidad de elevar a rango constitucional el derecho ciudadano a la sostenibilidad fiscal y el deber estatal de protegerlo.

De esta manera, un elemento crucial de las políticas públicas es la velocidad que se pueda dar a la "progresiva efectividad" del conjunto de derechos económicos y sociales y a la satisfacción de las necesidades básicas de las personas, a las que se refieren las Naciones Unidas y la jurisprudencia de la Corte.

Los derechos económicos y sociales deben verse de una forma dinámica y no se puede sacrificar la provisión futura de los mismos por una política fiscal insostenible. Corresponde al legislador la definición del contenido concreto de los derechos económicos y sociales en consideración de la estabilidad macroeconómica y por lo tanto la provisión futura de los mismos.

Pero la noción de derecho desapareció del proyecto, y se reemplazó por la noción de principio como criterio orientador. Como tal, la sostenibilidad fiscal no estaría sometida a reglas específicas sino a declaraciones orientadoras. No se podrá invocar la aplicación del principio de sostenibilidad fiscal "para menoscabar los derechos fundamentales". Esta sí que es una contundente declaración de principios que minimiza la tensión entre sostenibilidad y derechos y reduce drásticamente el alcance originario de los propósitos del Proyecto de Acto Legislativo.

Derecho, o principio, en todo caso queda abierta la cuestión fundamental; la ecuación de la sostenibilidad fiscal contiene un factor que prácticamente ha desaparecido del debate público: el factor tributario.

Para Antonio Hernández Gamarra y Luis Hernando Barreto Nieto, los factores tributarios son factores que reducen sin remedio las expectativas de una sociedad justa en un ambiente de sostenibilidad fiscal.

Roberto Steiner, Director Ejecutivo de Fedesarollo, indicó: "Ese proyecto es en realidad un artículo muy breve. Propone que en la Constitución se establezca la estabilidad fiscal como un derecho colectivo de los ciudadanos".

"Lo que busca esta propuesta, presentada por el gobierno anterior, es darle herramientas a los jueces de la República, quienes continuamente se ven enfrentados a tutelas que los obligan a ordenar más gasto público. Generalmente estas quejas hacen referencia al derecho a la salud, que ha sido determinado como fundamental. Entonces los jueces argumentan que ellos hacen cumplir lo que dicta la Carta Magna y el tema de sostenibilidad fiscal no está estipulado alli”. 
Según Steiner, los colombianos necesitamos un Estado que proteja todos los derechos y que garantice los recursos para pagarlos y por eso, en su concepto, a los jueces hay que darles las herramientas para que sepan el impacto de sus decisiones de carácter económico sin que se violen los derechos fundamentales.

Sobre la meta de equidad intergeneracional, el director de Fedesarrollo explicó que "el tema se basa en la idea de que se avecina un importante ingreso de los dineros minero-energéticos, y no parece ser razonable que esta generación se lo gaste todo. Entonces, el Gobierno quiere crear mecanismos para que parte de ese dinero se ahorre y pueda ser gastado por futuras generaciones".

Sin embargo, para el profesor Jorge Armando Rodríguez, investigador del Centro de Investigaciones para el Desarrollo (CID), de la UN, "tener unas finanzas sanas y sostenibles es un objetivo deseable, pero es desacertado consagrar la sostenibilidad fiscal como un derecho en la Constitución. Hay mecanismos más idóneos para lograr ese propósito y no se puede poner al mismo nivel la estabilidad con derechos como la libre expresión, la vida y la atención en salud".

La sostenibilidad fiscal enfrentó a los partidos políticos, a los economistas y a los constitucionalistas. Esta controversia llevó a que, en la discusión del Acto legislativo, la sostenibilidad fiscal pasara de derecho a principio y que, al final, terminara como criterio.

Según los congresistas, lo que pretendió el gobierno fue poner el Principio de Sostenibilidad Fiscal por encima de los Derechos Económicos y Sociales asociados al Estado Social de Derecho consagrado en la Constitución Política de 1991. Aducen los críticos que gran parte de las decisiones de la Corte Constitucional que han tenido impacto fiscal no han hecho más que reflejar la obligación que tiene el tribunal constitucional de velar porque se cumplan los principios económicos y sociales de la Constitución, incluidos el derecho a la salud, a la vivienda digna y a una remuneración móvil.
De hecho, me atrevo a pensar que una posible implicación de adoptar el Principio orientador de Sostenibilidad no es la de que se recorte algún derecho económico y social sino, más bien, que el Estado disponga, efectivamente, de los recursos financieros suficientes para reconocer los derechos fundamentales de los ciudadanos.

El Acto Legislativo establece que la sostenibilidad fiscal debe fungir como instrumento para alcanzar, de manera progresiva, los objetivos del Estado Social de Derecho. Igualmente, determina que el plan de inversiones públicas y el financiamiento para su ejecución deben estar enmarcados en dicha sostenibilidad

La Reforma crea una figura novedosa que se denomina Incidente de Impacto Fiscal. Gracias a este, el Procurador o uno de los Ministros están en capacidad de conseguir que, en razón a las consecuencias que las sentencias proferidas por cualquiera de las máximas corporaciones judiciales puedan tener sobre las finanzas públicas, los efectos de las mismas se puedan modular, modificar o diferir, sin que en ningún caso se afecte el núcleo esencial de los derechos fundamentales.

Aunque a algunos economistas no los satisface la solución de hacer de la sostenibilidad fiscal un criterio y no un derecho, y a un grupo de constitucionalistas les parece que con este Acto Legislativo se está arrasando con los fundamentos del Estado Social de Derecho, la realidad es que el Congreso consiguió establecer un equilibrio razonable entre las diferentes posiciones, pues al tiempo que se preserva el logro progresivo de los objetivos del Estado Social de Derecho, ello se hace en un marco de sostenibilidad fiscal y de colaboración armónica entre las diferentes ramas y órganos del Poder Público.

En concordancia, el nuevo texto sólo hace referencia a que el Principio de Sostenibilidad Fiscal debe orientar la acción armónica de las ramas y órganos del poder público. 


\section{RESPONSABILIDAD DE LOS DISTINTOS ÓRGANOS DEL PODER PÚBLICO EN ARAS DE LASOSTENIBILIDAD FISCAL.}

Siendo la sostenibilidad fiscal un asunto que incumbe al interés público y a la prosperidad general, conviene destacar la importancia que reviste la acción coordinada por parte de las distintas autoridades que, al interior del Estado, ejercen funciones que inciden de manera preponderante sobre la misma. Nos referimos específicamente al Legislador, al Ejecutivo, a los jueces, al propio Banco de la República y a las diversas autoridades territoriales.

Al respecto, no sobra recordar el precepto general que contiene el artículo 113, inciso tercero, de la Carta Política, conforme al cual "Los diferentes órganos del Estado tienen funciones separadas pero colaboran armónicamente para la realización de sus fines." El Acto Legislativo invita, explícitamente, a considerar que para realizar tales fines es indispensable lograr la sostenibilidad fiscal la cual debe orientar a las Ramas y Órganos del Poder Público para la realización del Estado Social de Derecho.

En lo que atañe específicamente a la materia económica, el artículo 371 de la Carta Política, al definir las funciones básicas del Banco de la República, señala en su inciso segundo que "Todas ellas se ejercerán en coordinación con la política económica general".

Ausencia de otras normas constitucionales explícitas sobre la coordinación de políticas para alcanzar la sostenibilidad fiscal. El acto legislativo, prevé en su artículo primero, añadir al artículo 334 de la Constitución un nuevo precepto que ordene a todas las ramas y órganos del poder público, colaborar armónicamente en procura de la sostenibilidad fiscal del país.

\section{CONCLUSIÓN}

Como bien se ha dicho, las constituciones políticas deben consagrar los principios y reglas fundamentales que gobiernan la estructura $y$ orientación del Estado. No deben caer, por tanto, en reglamentaciones excesivas, ni en lo casuístico, ni pretender solucionar problemas meramente coyunturales.

En este orden de ideas, se ha dado en llamar "constitución económica" al conjunto de normas constitucionales que definen los principios fundamentales sobre los cuales descansa la actividad económica del Estado y de los particulares El propósito de la sostenibilidad fiscal en el Estado social de derecho es que busca que las diferentes ramas y órganos del poder público trabajen armónicamente por el cumplimiento del nuevo postulado constitucional y según sus competencias, se involucren y tengan presente la sostenibilidad fiscal como un derecho de todos y la responsabilidad del Congreso de la República de velar por el cumplimiento de dichos preceptos al momento de legislar sobre el alcance y contenido de los derechos económicos y sociales, con el propósito de brindarles garantía de progresividad.

La propuesta de Acto Legislativo, tuvo por objeto proteger la efectividad de los derechos propios del Estado Social de Derecho ante los diversos avatares del ciclo económico nacional e internacional, incorporando en la "Constitución económica" el derecho a la sostenibilidad fiscal, así como el deber de las ramas y órganos del Estado de protegerlo, y como consecuencia contribuir a la continuidad y a la progresividad de los derechos económicos, sociales y culturales, en su conjunto.

Por estas razones, el Gobierno Nacional consideró necesario una iniciativa que otorgue, en forma expresa, jerarquía constitucional a la preservación y protección de la sostenibilidad fiscal, reconociendo el decisivo papel que ésta cumple como condición necesaria, que no suficiente, para el cumplimiento de los deberes sociales del Estado y la garantía de la 
efectividad de los derechos a través del crecimiento sostenido de la economía.

Con el proyecto de acto legislativo presentado por el gobierno se quiso establecer una disposición constitucional expresa que garantizara la prestación y el disfrute de los derechos económicos, sociales y culturales.

Sin embrago, alcanzar y garantizar la sostenibilidad fiscal requiere de un gran compromiso y disciplina del sector público y del apoyo de la sociedad en la búsqueda de este objetivo, pues de no garantizarla, los riesgos y los costos económicos y sociales pueden ser elevados.

Una interpretación sistemática y teleológica del Acto Legislativo 03 de 2011 permite arribar a las siguientes conclusiones:

a. La jerarquía de la sostenibilidad fiscal. La sostenibilidad fiscal tan sólo se concibe como un criterio de actuación, armonización y coordinación de las competencias de todas las autoridades públicas, incluidos los jueces constitucionales. No se trata, en consecuencia, del establecimiento de una prelación, de una jerarquía de la sostenibilidad fiscal sobre los DESC, sino del reconocimiento de que la vigencia de éstos depende de aquélla. Sin duda, los avances en materia de educación, salud, vivienda, entre otros, dependen de la viabilidad económica del Estado, de preservar su capacidad de endeudamiento interno e internacional, en un mundo globalizado y afectado por constantes y profundas crisis económicas.

b. El incidente de impacto fiscal. La nueva figura del incidente de impacto fiscal, antes que ser considerada como un instrumento que socave la autonomía judicial, pretende erigirse en un escenario procesal donde los jueces escuchen los argumentos de las demás ramas del poder público, a efectos de que ajusten sus fallos a los requerimientos de la sostenibilidad fiscal. c. El sentido de la "sostenibilidad fiscal" apunta a que exista un equilibrio fiscal, es decir, que los gastos previstos u ordenados para el pago de una sentencia estén previstos o presupuestados.

d. La judicialización de la economía. La maleabilidad del concepto de sostenibilidad fiscal, pone de manifiesto que el Acto Legislativo realiza una apuesta por la judicialización de la economía. Paradójicamente: se quería colocar límites severos al ejercicio de las competencias judiciales, en especial, aquellas de la Corte Constitucional en materia de DESC, y lo que se obtuvo fue que los jueces se erigieran en los principales árbitros sobre las decisiones económicas.

La Corte Constitucional ha proferido dos sentencias sobre el mencionado acto legislativo, la primera declarándose inhibida y la segunda declarando exequible el Acto legislativo.

Finalmente, en el Senado de la República, la sostenibilidad fiscal dejó de ser considerada en términos de "derecho", para transformarse en "principio orientador" de la colaboración entre las ramas del poder público con lo cual se afectaba el Estado social de derecho.

\section{REFERENCIAS BIBLIOGRÁFICAS}

- Trapaga Reyes, Jesús (2000). El derecho social en México: perspectivas y problemas, en el Cotidiano No. 99. pp. 5-6).

- Caceres, C., Corbacho, A., \& Medina, L. (2010). Structural Breaks in Fiscal Performance: Did Fiscal Responsibility Laws Have Anything to Do with Them. International monetary fund (IMF).

- Restrepo Piedrahita, C. (1995) Constituciones Políticas Nacionales de Colombia, Bogotá, Universidad Externado de Colombia.

- Banco de la República. Consolidar y blindar las finanzas públicas de Colombia, en Borradores de economíaNo 505, Bogotá, Banco de la República 2008.

- Banco Interamericano de Desarrollo, HA-L1034: Sostenibilidad Fiscal. Washington, 29-abr-2010. 
- Centro de Investigaciones para el Desarrollo (CID), de la UN, La sostenibilidad fiscal, Bogotá, Unal, 2012.

- Fedesarrollo (2010). La Regla Fiscal. Economía y Política, número 64 Bogotá.

- Fedesarrollo (2011). "Las bondades del acto legislativo sobre sostenibilidad fiscal". Economía y Política, número 66 Bogotá.

- Fedesarrollo (2012). Títulos debates de coyuntura económica y social No .93 Agosto Bogotá.

- FMI (2010) "Fiscal Monitor, Navigating the Fiscal Challenge Ahead",Fiscal Affairs Department, Washington.

- FMI "Fiscal Rules Anchoring Expectations for Sustainable Public Finances," Staff Paper, Washington, 2010

- Landau, D. (2010) "Political Institutions and judicial role in comparative constitutional law". Harvard International Lawjournal. Volume 51.

- Lozano I. y Cabrera E. (2009). Sostenibilidad fiscal en Colombia: una mirada hacia el mediano plazo, en Borradores de economía No 579 Banco de la República, Bogotá.

- Lozano I., Rincón Hernán, Sarmiento Miguel Y Ramos Jorge. (2010). Regla fiscal cuantitativa para Colombia. En Borradores de economía No 593 Banco de la República, Bogotá.

- Ministerio de Hacienda y Crédito Público Exposición de motivos al proyecto de acto legislativo "Por el cual se establece el derecho a la sostenibilidad fiscal para alcanzar los fines del Estado Social de Derecho, Bogotá, 2011.

- ONU. Pacto Internacional de los Derechos Económicos, Sociales y Culturales, Washington, 1966.

\section{JURISPRUDENCIALES}

Cconst, C-449/1992,A. Martínez.

CConst, C-033/1999, C. Gaviria.

CConst, C-132/2012, H. Sierra.

CConst, C-242/2009, M. Gonzáles.

CConst, C-132/2012, H. Sierra.

CConst, C-1489/2000, A. Martínez.

CConst, C-408/1994, F. Morón.

CConst, C-481/1999, A. Martínez.

CConst, C-579/2001, M. Cepeda.

CConst, C-802/2006, M. Cepeda.

CConst, C-802/2006, M. Cepeda.

CConst, C-332/2012, H. Sierra.

\section{NORMATIVAS}

Acto Legislativo 3/2011

D. $111 / 1996$

L. $358 / 1997$

L. $819 / 2003$

L. $617 / 2000$

L. $1448 / 2011$

L. $1454 / 2011$

L. $1473 / 2011$

L. $819 / 2003$ 